\title{
Efeito da farinha de semente de abóbora (Cucurbita maxima, L.) sobre o metabolismo glicídico e lipídico em ratos ${ }^{1}$
}

\author{
The pumpkin (Cucurbita maxima, L.) seed \\ flour effect on the rat glucose and lipid metabolism
}

Priscila Machado de CERQUEIRA ${ }^{2}$

Maria Cristina Jesus FREITAS ${ }^{3}$

Matilde PUMAR ${ }^{4}$

Sabrina Barreiros SANTANGELO²

\section{R E S U M O}

\section{Objetivo}

O objetivo desta pesquisa foi avaliar o efeito da farinha de semente de abóbora (Cucurbita maxima, L.) sobre o metabolismo glicídico e lipídico em ratos.

\section{Métodos}

Vinte ratos Wistar machos recém-desmamados, distribuídos em quatro grupos, receberam por 10 dias, rações controle e experimental com farinhas de semente de abóbora integral, peneirada ou residual substituindo $30 \%$ do valor total de amido e dextrina da dieta controle. As dietas foram isocalóricas. Foram determinados os macronutrientes e a fibra insolúvel nas farinhas. As dietas tiveram a composição química calculada a partir dos dados dos rótulos dos produtos, da tabela de composição de alimentos e da análise química das farinhas de semente de abóbora. O peso corporal e a ingestão dos animais foram tomados a cada 48 horas. O sangue, coletado por punção cardíaca, teve os níveis de triacilgliceróis, colesterol e glicose analisados por métodos enzimáticos.

\section{Resultados}

As farinhas de semente de abóbora foram boas fontes de proteínas, lipídeos e, especialmente, fibras alimentares. Os animais tiveram ganho ponderal e ingestão semelhante $(p>0,05)$. Os níveis de glicose e triacilgliceróis foram reduzidos significantemente para os grupos que receberam dietas com farinhas de semente de abóbora integral e peneirada.

\footnotetext{
1 Artigo elaborado a partir da dissertação de P.M. CERQUEIRA, intitulada: "Avaliação da farinha de semente de abóbora (Cucurbita maxima, L.) no trato intestinal e no metabolismo glicídico e lipídico em ratos”. Universidade Federal Rural do Rio de Janeiro; 2006.

${ }^{2}$ Universidade Federal Rural do Rio de Janeiro, Departamento de Ciência e Tecnologia de Alimentos. Seropédica, RJ, Brasil.

3 Universidade Federal do Rio de Janeiro, Instituto de Nutrição Josué de Castro. Av. Brig. Trompowsky, s/n., Bloco J, Ilha do Fundão, 21941-590, Rio de Janeiro, RJ, Brasil. Correspondência para/Correspondence to: M.C.J. FREITAS. E-mail: <cristina@nutricao.ufrj.br>.

${ }^{4}$ Universidade do Estado do Rio de Janeiro, Instituto de Nutrição. Rio de Janeiro, RJ, Brasil.
} 


\section{Conclusão}

Frente às suas propriedades química e funcional, concluiu-se que a farinha de semente de abóbora interferiu no metabolismo do rato diminuindo significantemente os níveis de glicose e triacilgliceróis séricos.

Termos de indexação: Farinha. Fibra alimentar. Metabolismo dos lipídeos. Ratos. Sementes.

\section{A B S T R A C T}

\section{Objective}

The aim of the present research was to evaluate the pumpkin (Cucurbita maxima, L.) seed flour effect on the rat glucose and lipid metabolism.

\section{Methods}

Twenty recent weaned male Wistar rats, divided in four groups, received for 10 days control and experimental diets containing whole, sifted and residual pumpkin seed flour on the rate of $30 \%$ of the total starch and dextrin in the control diet. All diets were isocaloric. Macronutrients and insoluble fiber were determined in the flours. All diets had their chemical composition calculated based on data from product labels, of food composition table and of the chemical analysis of the pumpkin seed flours. The animals' growth and ingestion had been evaluated in 48 hours intervals. Blood samples drawn by cardiac puncture had their triacilglycerides, cholesterol and glucose levels measured by enzymatic methods.

\section{Results}

The pumpkin seed flour are good protein, lipids and, specially, dietary fiber sources. The animals' growth and food ingestion were similar along all the experiment ( $p>0.05$ ). Glucose and triacilglycerides were significantly decreased in the groups taking diets with whole- and sifted-pumpkin seed flour respectively.

\section{Conclusion}

Taking into account their properties chemistry and functional, it can be concluded that the pumpkin seed flour interfered in the rat metabolism decreasing significantly the serum glucose and triacilglycerides levels.

Indexing terms: Flour. Dietary fiber. Lipid metabolism. Rats. Seeds.

\section{N T R O D U ÇÃ O}

A fibra alimentar é descrita como uma classe de compostos de origem vegetal que, quando ingeridos, são resistentes à hidrólise enzimática, à digestão e à absorção no intestino delgado, apresentando fermentação parcial no intestino grosso ${ }^{1,2}$. Estes compostos de origem vegetal incluem polissacarídeos, oligossacarídeos, lignina e substâncias associadas.

Os efeitos fisiológicos exercidos pela fibra alimentar são: laxação, aumento do bolo fecal, atenuação do colesterol e da glicemia sanguínea, entre outros ${ }^{3}$. Dentre outros fatores, isto se relaciona à sua solubilidade em água, podendo as fibras serem classificadas em solúveis (pectinas, gomas e mucilagens) e insolúveis (celulose, hemicelulose e lignina)
A reduzida ingestão de fibra alimentar pelo homem vem sendo associada ao aumento de inúmeras doenças crônicas não transmissíveis. Dessa forma, o consumo de alimentos ricos em fibra alimentar é essencial para manter a saúde e reduzir os riscos de determinadas doenças como diabetes mellitus e dislipidemias ${ }^{2,4}$. Para suprir o déficit do consumo de fibra alimentar, a indústria alimentícia vem utilizando a fibra para produção ou enriquecimento de seus produtos e, desta forma, aumentar o teor de fibra alimentar e também nutricional. As fontes alternativas de fibra alimentar podem trazer grandes vantagens para as indústrias alimentícias, pois contribuem para o enriquecimento de produtos e previnem contra o desperdício, uma vez que o alimento é utilizado integralmente ${ }^{5}$. 
Dentre diversas fontes alimentares alternativas ricas em fibra, pode-se citar um dos subprodutos da abóbora, a semente. A abóbora pertence à ordem Cucurbitales, família Cucurbitaceae e espécie Cucurbita, sendo utiliza$\mathrm{da}$, principalmente, em seu estado maduro para compor a dieta. A semente de abóbora também é utilizada pela medicina popular brasileira. Estudos em animais não demonstraram o efeito tóxico desse tipo de semente. Entretanto, seu consumo, in natura, sem sofrer tratamento térmico prévio, poderá diminuir a biodisponibilidade de determinados nutrientes ${ }^{3}$.

Estudos mostram ${ }^{1,2}$ o efeito benéfico da semente de abóbora sobre o metabolismo, a fisiologia e a nutrição humana. Entretanto os medicamentos hipotensivos, felodipina e captopril, tiveram seu efeito potencializado em associação com o óleo de semente de abóbora ${ }^{4}$.

A semente de abóbora está sendo aplicada de várias formas na alimentação humana como aperitivo, óleo ou em forma de farinha (FSA). A farinha possui elevado teor de fibra alimentar, efeito vermífugo e antioxidante, e representa, também, uma boa fonte protéica ${ }^{5}$.

Em razão da contribuição positiva da fibra alimentar à saúde, do alto teor de fibra da semente de abóbora e considerando a carência de dados sobre o estudo comparativo das aplicações nutricionais da fibra alimentar de semente de abóbora, o objetivo deste trabalho foi avaliar os efeitos da FSA no metabolismo glicídico e lipídico de ratos.

\section{M É T O D O S}

Sementes obtidas de abóboras baianas (Cucurbita maxima, L.), provenientes da Central de Abastecimento do Rio de Janeiro (CEASA-RJ), foram higienizadas e sanitizadas, secas em estufa ventilada a $40^{\circ} \mathrm{C}$ por $18 \mathrm{~h}$, e armazenadas a $-18^{\circ} \mathrm{C}$ para posterior utilização. Foram, então, torrefadas em fogo brando $\left(150\right.$ a $\left.180^{\circ} \mathrm{C}\right)$, por 10 a 15 minutos, e resfriadas em tabuleiros à temperatura ambiente. Uma parte das sementes torrefadas foi triturada em liquidificador e passada em peneira doméstica, obtendo-se a FSA-Peneirada e a FSA-Residual. O restante dessas sementes foi triturado em liquidificador e, posteriormente, em moinho RETSCH malha 0,5mm, por 3 minutos, obtendo-se a FSA-Integral.

A fibra insolúvel foi determinada pelo método de Van Soest ${ }^{6}$, modificado por Mendez et al. ${ }^{7}$. Umidade, cinza, lipídeos e proteína bruta foram determinados de acordo com o Instituto Adolfo Lutz $z^{8}$. O fator de conversão de teor do nitrogênio dosado para proteína usado foi $5,7^{9}$ e os glicídios calculados por diferença das demais análises.

A dieta controle foi elaborada de acordo com Reeves et al. ${ }^{10}$. Para a dieta de manutenção e para as dietas experimentais substituiu-se 30\% do teor total de carboidratos (amido e dextrina), da dieta controle, pelas FSA correspondentes, conforme Tabela 1.

A composição química das dietas foi calculada utilizando dados dos rótulos dos produtos, da tabela de composição de alimentos ${ }^{11}$ e das análises químicas realizadas nas FSA.

Foram utilizados 20 ratos Wistar machos recém-desmamados do Laboratório de Nutrição Experimental da Universidade Federal Fluminense (LABNE/UFF), que receberam ração comercial

Tabela 1. Formulação das dietas controle e de farinha de semente de abóbora. Rio de Janeiro (RJ), 2005.

\begin{tabular}{|c|c|c|c|c|}
\hline \multirow{3}{*}{ Componentes } & \multicolumn{4}{|c|}{$\operatorname{Dietas}(\mathrm{g} / \mathrm{kg})^{1}$} \\
\hline & \multirow{2}{*}{ Controle } & \multicolumn{3}{|c|}{ Farinha de semente de abóbora } \\
\hline & & Integral & Peneirada & Residual \\
\hline Amido de milho ${ }^{2}$ & 465,7 & 325,9 & 325,9 & 325,9 \\
\hline Dextrina $^{2}$ & 155,0 & 108,6 & 108,6 & 108,6 \\
\hline FSA & - & 186,2 & 186,2 & 186,2 \\
\hline Caseína ${ }^{2}$ & 140,0 & 140,0 & 140,0 & 140,0 \\
\hline Sacarose & 100,0 & 100,0 & 100,0 & 100,0 \\
\hline Óleo de soja & 40,0 & 40,0 & 40,0 & 40,0 \\
\hline Fibra-celulose ${ }^{2}$ & 50,0 & 50,0 & 50,0 & 50,0 \\
\hline Mistura mineral² & 35,0 & 35,0 & 35,0 & 35,0 \\
\hline Mistura vitamínica² & 10,0 & 10,0 & 10,0 & 10,0 \\
\hline L-cistina ${ }^{2}$ & 1,8 & 1,8 & 1,8 & 1,8 \\
\hline Colina (bitartarato) ${ }^{2}$ & 2,5 & 2,5 & 2,5 & 2,5 \\
\hline
\end{tabular}

${ }^{1}$ Reeves et al. ${ }^{10 ;}{ }^{2}$ Obtidas no Comércio e Indústria Farmos Ltda. 
para ratos até atingirem peso de $110 \mathrm{~g}$ a $125 \mathrm{~g}$, passando, então, a receber as dietas experimentais durante 10 dias.

Os animais foram distribuídos em 4 grupos com peso médio semelhante, com diferença máxima de $5 \%$, cada grupo contendo 5 animais. Os ratos foram alocados em gaiolas de polipropileno individuais, e cobertas com maravalhas, e mantidos no biotério sob temperatura média de $21^{\circ} \mathrm{C}$, com alternância de período de 12 horas de claro-escuro. Tiveram acesso livre a dieta e a água. $\mathrm{O}$ peso corporal e a quantidade de ingestão foram tomados a cada $48 \mathrm{~h}$ correspondendo aos tempos T1, T2, T3, T4 e T5.

O presente experimento foi apreciado pelo Comitê de Ética da Universidade Federal do Rio de Janeiro cumprindo as exigências e os procedimentos com animais contidos na Declaração de Helsinki ${ }^{12}$ e as condutas do COBEA por Goldenberg $^{13}$, artigos I, IV, VIII e XI. Protocolo número INJC001.

Após o término do período de experimento, os animais foram colocados em jejum por 12 horas. Em seguida, e sob anestesia, foram coletadas amostras de sangue por punção cardíaca, nas quais foram analisados triacilgliceróis, colesterol e glicose séricos. Todas as amostras foram analisadas em duplicata considerando erro máximo de $5 \%$ entre os resultados. As determinações de triacilgliceróis (GPO-ANA) e colesterol (COD-ANA) foram feitas por métodos enzimáticos ${ }^{14,15} \mathrm{e}$ a glicose sérica, pelo método enzimático da glicose-oxidase (GOD-PAD) ${ }^{16}$.

Todos os parâmetros quantificados no estudo foram avaliados por análise de variância (ANOVA) e teste de Tukey com nível de confiança de $95 \%$, usando o software Statistical versão 6.0 ${ }^{17}$.

\section{RESULTADOSE DISCUSS Ã O}

Conforme resultados obtidos (Tabela 2), verifica-se que os teores de umidade das farinhas estão de acordo com a legislação brasileira, que estipula até $15 \%$ para farinhas comerciais ${ }^{18}$. Os valores de cinzas das FSAs foram próximos aos encontrados por Achu et al. ${ }^{19}$, que estudaram cinco espécies de sementes de Cucurbitaceae - entre 3,47 e $4,75 \mathrm{~g} / 100 \mathrm{~g}$. Os resultados também evidenciaram elevados teores de fibra alimentar, proteínas e lipídeos nas amostras de FSAs.

Dados na literatura, semelhantes aos obtidos, mostram significativos teores de fibras alimentares, proteínas e lipídeos em sementes vegetais. E que dentre as fibras alimentares totais, a fração insolúvel é predominante ${ }^{20}$. Os diferentes valores absolutos dos macronutrientes (proteína e lipídeos) e de fibra alimentar (fibra detergente neutro) podem ser explicados pelas diferentes FSAs (Integral, Peneirada e Residual) obtidas ao final do processamento. Assim, maiores valores de fibra alimentar são esperados na FSA-Residual, composta, basicamente, pela parede celular vegetal-tegumento, ou seja, a casca da semente. A manutenção do endosperma das sementes para elaborar as FSAs Integral e Peneirada pode justificar o maior teor de lipídeos.

Embora trabalhando com metodologia diferente da apresentada, os autores: Esuoso et al. ${ }^{5}$ e Samant \& Rege ${ }^{21}$ encontraram alto teor de fibra bruta nas espécies da família Cucurbitáceas além do alto teor de fibra bruta $(9,3 \%)$ na semente de abóbora (Telfairia occidentalis); também constataram o mesmo para proteínas $(16,0 \%)$ e lipídeos (48,6\%).

Os valores de proteína e lipídeos das FSAs estudadas foram inferiores aos de Younis et al. ${ }^{22}$,

Tabela 2. Composição química das farinhas de semente de abóbora. Rio de Janeiro (RJ), 2005

\begin{tabular}{lrrr}
\hline \multirow{2}{*}{ Componentes } & \multicolumn{3}{c}{ Farinha de semente de abóbora $(\mathrm{g} / 100 \mathrm{~g})^{\mathbf{1}}$} \\
\cline { 2 - 4 } & Integral & Peneirada & Residual \\
\hline Umidade & $8,41^{\mathbf{a}}$ & $7,80^{\mathbf{b}}$ & $8,36^{\mathbf{a}}$ \\
Cinzas & $4,32^{\mathbf{a}}$ & $4,27^{\mathbf{a}}$ & $3,19^{\mathbf{b}}$ \\
Proteína & $25,69^{\mathbf{b}}$ & $28,68^{\mathbf{a}}$ & $25,34^{\mathbf{b}}$ \\
Lipídeos & $31,76^{\mathbf{a}}$ & $32,96^{\mathbf{a}}$ & $19,28^{\mathbf{b}}$ \\
Fibra alimentar (NDF) & $29,49^{\mathbf{b}}$ & $24,88^{\mathbf{b}}$ & $43,51^{\mathbf{a}}$ \\
Carboidratos totais & $0,33^{\mathbf{b}}$ & $1,41^{\mathbf{a}}$ & $0,31^{\mathbf{b}}$ \\
Kcal & 389,92 & 417,00 & 276,12 \\
\hline
\end{tabular}

1 Médias seguidas de letras iguais na mesma linha não diferenciam entre si com nível de significância de $5 \% ;{ }^{2}$ Calculado por diferença. 
que encontraram, em sementes de Cucurbita pepo L , aproximadamente: 38,0\% de proteína, 37,0\% de carboidrato, e 35,0\% de óleo, sendo este, composto de 78,0\% de ácidos graxos insaturados.

Achu et al. ${ }^{19}$ avaliaram o valor nutritivo de 5 espécies de Cucurbitaceae. O valor médio protéico da Cucumi stuvus foi de 28,68\% (Desvio-padrão - DP=2,38), próximo ao encontrado para as três FSAs; já o conteúdo de fibras alimentares foi inferior $(3,44 \%)$ na semente da Cucurbita maxima. Também concluíram que as sementes de Cucurbitaceae, em geral, podem ser consideradas fontes de óleos e proteínas.

Na Tabela 3 apresenta-se a composição nutricional das 4 dietas utilizadas nos 10 dias de experimento. As dietas experimentais isocalóricas foram suficientes para desenvolvimento dos animais e se distinguiram, sobretudo, no teor de fibra alimentar contido nas sementes de abóbora.

Apesar de os animais submetidos às FSAs terem apresentado ligeira elevação no consumo ( $1 \%$ a $10 \%$ ) em relação ao controle, no período avaliado, o consumo médio em todos os tempos do experimento não diferiu estatisticamente $(p>0,05)$ entre todos os grupos. A composição da semente de abóbora, por possuir maior teor de fibra insolúvel, pode ter causado este incremento na ingestão. Alguns autores também já haviam observado o aumento do consumo alimentar em função da presença de fibras insolúveis na dieta 23,24 .

Tabela 3. Composição nutricional das dietas controle e experimental contendo FSAs.Rio de Janeiro (RJ), 2005.

\begin{tabular}{lrrrr}
\hline \multirow{2}{*}{ Componentes } & \multicolumn{4}{c}{ Dietas $(\mathrm{g} / 100 \mathrm{~kg})^{\mathbf{1}}$} \\
\cline { 2 - 5 } & & \multicolumn{4}{c}{ Farinha de semente de abóbora } \\
\cline { 2 - 5 } & 12,0 & 12,3 & 17,6 & 16,8 \\
\hline Proteína & 4,3 & 10,3 & 10,3 & 7,7 \\
Lipídeos & 65,2 & 48,7 & 47,9 & 47,7 \\
Carboidratos totais & 5,0 & 10,6 & 9,72 & 13,3 \\
Fibra alimentar & 3,5 & 3,5 & 3,5 & 3,5 \\
Mistura mineral & 1,0 & 1,0 & 1,0 & 1,0 \\
Mistura vitamínica & 347,5 & 336,7 & 354,7 & 327,3 \\
\hline Kcal & \multicolumn{4}{c}{} \\
\hline 1 Reeves et al. ${ }^{10}$. & &
\end{tabular}

Assim, as propriedades químico-físicas da fibra, sua fonte de origem e a forma como é aplicada, são alguns dos fatores que podem influenciar o consumo da dieta e o desenvolvimento ponderal, o que justifica os resultados encontrados.

Com relação ao peso corpóreo, os animais iniciaram o experimento com peso médio de $110 \mathrm{~g}$ entre os grupos e o finalizaram com peso médio de $150 \mathrm{~g}$, sendo o crescimento ponderal semelhante $(p>0,05)$ para todos os grupos em todos os tempos do experimento. De acordo com os resultados obtidos, a incorporação das FSAs como fonte de fibra alimentar não interferiu no ganho de peso corpóreo dos ratos estudados. SemeIhante comportamento ponderal foi encontrado na literatura, em estudo que adicionou fibras alimentares à dieta de animais ${ }^{23}$.

Ao realizar a coleta observou-se que o sangue dos ratos alimentados com as dietas experimentais (contendo FSAs) diferiu sob alguns aspectos. Assim, o sangue destes grupos era, aparentemente, mais viscoso, formava gel e coagulava rapidamente, dificultando a coleta. Krishnamoorthi et al. ${ }^{25}$ relataram a presença do Fator Hageman ou Fator XII, responsável pelo processo de coagulação sangüínea na semente de abóbora. Esta proteína ativa outros fatores de coagulação, e o seu excesso pode reduzir o tempo de tromboplastina e acelerar a coagulação.

O impacto das dietas sobre os indicadores bioquímicos foi avaliado pelos valores séricos de glicose, de triacilglicerol e de colesterol, após 10 dias de experimento, e são apresentados na Tabela 4. Os animais que receberam dietas acrescidas das FSAs apresentaram, de modo geral, níveis séricos de glicose e triacilgliceróis reduzidos (em maior ou menor grau). Estudo in vitro, realizado por Chau \& Huang ${ }^{26}$, mostrou que a fração insolúvel da fibra, presente na semente do maracujá (Passiflora edulis), pode diminuir a glicose sérica e exercer efeito inibitório sobre a amilase. Da mesma forma, Chau et al. ${ }^{27}$ constataram a ação hipoglicemiante da fração insolúvel da fibra alimentar proveniente da polpa de cenoura, sugerindo o controle da glicose pós-prandial. 
Tabela 4. Níveis séricos de glicose, triacilgliceróis e colesterol total após 10 dias de experimento. Rio de Janeiro (RJ), 2005.

\begin{tabular}{|c|c|c|c|c|}
\hline \multirow{3}{*}{$\begin{array}{l}\text { Indicadores } \\
\text { bioquímicos }\end{array}$} & \multicolumn{4}{|c|}{ Grupos de animais $(\mathrm{mg} / \mathrm{dL})^{1}$} \\
\hline & \multirow{2}{*}{ Controle } & \multicolumn{3}{|c|}{ Farinha de semente de abóbora } \\
\hline & & Integral & Peneirada & Residual \\
\hline Glicose & $82,50^{\mathrm{a}}$ & $32,43^{b}$ & $58,31^{\text {ab }}$ & $52,43^{\mathrm{ab}}$ \\
\hline Triacilgliceróis & $150,80^{\mathrm{a}}$ & $113,33^{\mathrm{ab}}$ & $82,13^{b}$ & $89,33^{a b}$ \\
\hline Colesterol total & $105,55^{a}$ & $95,30^{\mathrm{a}}$ & $78,25^{a}$ & $67,45^{\mathrm{a}}$ \\
\hline
\end{tabular}

1 Letras iguais na mesma linha não diferem entre si $(p>0,05)$.

Com relação ao grupo controle, os animais submetidos às FSAs, embora não tenham apresentado diferença $(p>0,05)$ nos níveis de colesterol sérico total, pôde-se constatar valores inferiores em $10 \%, 26 \%$ e $36 \%$, respectivamente. Tais resultados podem estar relacionados com o alto teor de fibras, em especial a fração insolúvel nas dietas experimentais, fato já constatado por Chau et al. ${ }^{23}$. O resultado do presente trabalho, no que diz respeito à influência da ingestão de fibras insolúveis sobre níveis séricos de lipídeos, também já havia sido verificado por Chau et al. ${ }^{28}$, que os relacionaram ao tipo de fibra estudada e às suas propriedades físico-químicas.

De acordo com Samant \& Rege ${ }^{21}$, a celulose é o principal carboidrato da fração insolúvel presente na semente de abóbora. Ao estudarem o efeito de fibras alimentares, entre elas, a celulose sobre lipídeos séricos de ratos Wistar hiperlipidêmicos, Fietz \& Salgado ${ }^{28}$ observaram que, no $30^{\circ}$ dia de experimento, dietas com $10 \%$ e $15 \%$ de celulose proporcionaram redução significante do colesterol sérico em relação ao grupo controle. Piedade \& Canniatti-Brazaca ${ }^{24}$ compararam o efeito do resíduo do abacaxizeiro (caules e folhas) e da pectina cítrica de alta metoxilação, no nível de colesterol sangüíneo em ratos nos períodos de 15, 30 e 45 dias. No estudo verificaram que o resíduo do abacaxizeiro (cuja composição é predominante de fibra insolúvel) reduziu o nível de colesterol total e LDL-colesterol em todos os tempos avaliados e aumentou o HDL-colesterol para os tempos 15 e 30 dias.
Por outro lado, sabe-se que o efeito hipolipidêmico não está somente ligado à fibra alimentar. Os baixos níveis séricos de triacilgliceróis e colesterol encontrados nos ratos experimentais, também podem estar relacionados ao alto teor de ácidos graxos insaturados e de antioxidantes presente na semente abóbora ${ }^{19,22}$. O óleo de semente de abóbora - por apresentar considerável teor de ácidos monoinsaturados e polinsaturados, principalmente - auxiliaria no tratamento de dislipidemias. Segundo Al-Zuhair et al. ${ }^{29}$, o óleo de semente de abóbora foi capaz de potencializar o efeito medicamentoso da sinvastatina no tratamento de hipercolesterolemia. Isso sugere que a administração do óleo de semente de abóbora, em associação a doses reduzidas daquele medicamento, seria eficaz no tratamento de hipercolesterolemia.

Pelo que foi constatado na literatura e, segundo os resultados desta pesquisa com a semente de abóbora, é necessário ressaltar a importância de avanços tecnológico-científicos no estudo com vegetais, a fim de os incorporar com freqüência na alimentação devido aos seus benefícios.

\section{O N CLUS Ã O}

As FSAs (peneirada, residual e integral) apresentam alto teor de fibras alimentares, em especial a fibra insolúvel e também teores relevantes de proteína e de lipídeos. A adição de FSAs à dieta não alterou o consumo e o ganho de peso entre os animais experimentais. A FSA Integral foi mais eficiente na redução da glicemia, enquanto a FSA Peneirada exerceu maior efeito sobre o triacilglicerídeo sérico. Todas as FSAs tenderam a valores inferiores no colesterol sérico total. Os resultados obtidos na pesquisa reforçam o potencial da semente de abóbora como fonte de proteínas, lipídeos e fibras insolúveis, comuns ao consumo humano, ou como alternativa exercendo efeito benéfico sobre o metabolismo lipídico e glicídico. 


\section{A GRADECIMENTO}

À Coordenação de Aperfeiçoamento Pessoal de Nível Superior, pela concessão da bolsa de Mestrado.

\section{O LABORADORES}

P.M. CERQUEIRA executou o experimento biológico e elaborou o artigo. S.B. SANTANGELO contribuiu na execução do ensaio biológico e nas análises séricas dos animais, bem como nas análises química da farinha de semente de abóbora. M.C.J. FREITAS planejou e executou o delineamento do experimento biológico, supervisionou e coordenou todas as atividades e etapas do presente trabalho, analisou e interpretou os dados e a elaboração do artigo. M. PUMAR planejou e coordenou o experimento biológico, analisou e interpretou os dados e a elaboração do artigo.

\section{REFERÊ N CIAS}

1. Trowell H. Definition of dietary fiber and hypothesis that is a protective factor in certain diseases. Am J Clin Nutr. 1976; 29(4):417-27.

2. Rodríguez R, Jiménez A, Fernández-Bolaños J, Guillén R, Heredia, A. Dietary fibre from vegetable products as source of functional ingredients. Trends Food Sci Technol. 2006; 17(1):3-15.

3. Del-Vechio G, Corrêa AD, Abreu CMP, Santos CD. Efeito do tratamento térmico em sementes de abóboras (Cucurbita spp.) sobre os níveis de fatores antinutricionais e/ou tóxicos. Ciênc Agrotecnol. 2005; 29(2):369-76.

4. Al-Zuhair H, Fattah AAA, Sayed MI. Pumpkin-seed oil modulates the effect of felodipine and captopril in spontaneously hypertensive rats. Pharmacol Res. 2000; 41(5):555-63.

5. Esuoso K, Lutz H, Kutubuddin M, Bayer E. Chemical composition and potential of some underutilized tropical biomass. I: fluted pumpkin (Telfairia occidentalis). Food Chem. 1998; 61(4):487-92.

6. Van Soest PJ. Use of detergents in the analysis of fibrous feeds I: preparation of fiber residues of low nitrogen. J Assoc Of Anal Chem. 1963; 46:825-9.

7. Mendez MHM, Derivi SCN, Rodriguez MCR, Fernandes ML, Machado RLD. Método da fibra detergente neutro modificado para amostras ricas em amido. Ciênc Tecnol Aliment. 1985; 5(2): 123-31.

8. São Paulo. Instituto Adolfo Lutz. Normas analíticas do Instituto Adolfo Lutz: métodos analíticos e físicos para análise de alimentos. 3a. ed. São Paulo: IAL; 1985. v.1.

9. Jones DB. Factors for converting percentages of nitrogen in foods and feeds into percentage of protein. 22th ed. Washington (DC): USDA; 1941.

10. Reeves PG, Nielsen FH, Fahey GCJ. AIN-93 purified diets for laboratory rodents: final report of the American Institute of Nutrition and ad hoc Writing Commitee on the reformulation of the AIN-76. A rodent diet. J Nutr. 1993; 123:1939-51.

11. Philippi ST. Tabela de composição de alimentos: suporte para decisão nutricional. 2a. ed. São Paulo: Atheneu; 2002.

12. Declaração de Helsinki. Diretriz e normas regulamentadoras de pesquisas envolvendo seres humanos. Resolução 196/96. [acesso 2005 out 11]. Disponível em: <http://ufrgs.br/bioetica/ helsin5.htm>

13. Goldenberg S. Aspectos éticos da pesquisa com animais. Diretrizes e normas regulamentadoras de pesquisas envolvendo seres humanos (Resolução 196/96). Acta Cir Bras [periódico na internet] 2000 [acesso 2006 out 13]; 15(4):1-4. Disponível em: <http://www.ufrgs.br/bioetica/helsin5.htm>

14. Cooper C. Lipid and lipoprotein analysis. manual of laboratory operations lipid research clinics program. Washington (DC): NIH; 1974. v.1

15. Lopes-Virella MF, Stone P, Ellis S, Colwell JA. Cholesterol determination in high-density lipoproteins separated by three different methods. Clin Chem. 1977; 23(5):882-4.

16. Trinder P. Determination of glucose in blood using glucose oxidase with an alternative oxygen acceptor. Ann Clin Biochem. 1969; 6(24):24-7.

17. Pimentel-Gomes F. A estatística moderna na pesquisa agropecuária. Piracicaba: Kp Potafos; 1984.

18. Brasil. Portaria n. 354, de 18 de julho de 1996. Regulamento técnico para fixação de identidade e qualidade de farinha de trigo,farinha integral de trigo. Diário Oficial (da República Federativa do Brasil). 1996. 22 jul; Parte 1, Secção 1.

19. Achu MB, Fokou E, Tchiégang C, Fotso $M$, Tchouanguep FM. Nutritive value of some Cucurbitaceae oilseeds from different regions in Cameroon. Afr J Biotechnol. 2005; 4(11):1329-34.

20. Takemoto E, Okada IA, Garbelotti ML, Tavares M, Aued-Pimentel S. Composição química da semente e do óleo de baru (Dipteryx alata Vog.) nativo do 
Município de Pirenópolis, Estado de Goiás. Rev Inst Adolfo Lutz. 2001; 60(2):113-7.

21. Samant SK, Rege DV. Carbohydrate composition of some cucurbit seeds. J Food Comp Anal. 1989; 2(2):149-56.

22. Younis YM, Ghirmay S, Shihry S. African Cucurbita pepo L. Properties of seed and variabity in fatty acid composition of seed oil. Phytochemistry. 2000; 54(1):71-5.

23. Chau CF, Chen $\mathrm{CH}$, Wang YT. Effects of a novel pomace fiber on lipid and cholesterol metabolism in the hamster. Nutr Res. 2004; 24(5):337-45.

24. Piedade J, Canniatti-Brazaca SG. Comparação entre o efeito do resíduo do abacaxizeiro (caules e folhas) e da pectina cítrica de alta metoxilação no nível de colesterol sangüíneo em ratos. Ciênc Tecnol Aliment. 2003; 23(2):149-56.

25. Krishnamoorthi R, Gong Y, Richardson M. A new protein inhibitor of trypsin and activated Hageman factor from pumpkin (Cucurbita maxima) seeds. FEBS Lett. 1990; 273(1-2):163-7.
26. Chau CF, Huang YL. Characterization of passion fruit seed fibers-a potential fibre source. Food Chem. 2004; 85(2):189-94.

27. Chau CF, Chen $\mathrm{CH}$, Lee $\mathrm{M}$. Comparison of the characteristics, functional properties, and in vitro hypoglycemic effects of various carrot insoluble fiber-rich fractions. LWT. 2004; 37(2):155-160.

28. Fietz VR, Salgado JM. Pectin and cellulose effects on cholesterol serum levels, and triglycerides in hiperlipidemic rats. Ciênc Tecnol Aliment. 1999; 9(3):318-21

29. Al-Zuhair H, Abd El-Fattah AA, Abd el Latif H A. Efficacy of simvastatin and pumpkin-seed oil in the management of dietary-induced hypercholesterolemia. Pharmacol Res. 1997; 35(5):403-8.

Recebido em: 14/9/2006

Versão final reapresentada em: 20/7/2007 Aprovado em: 29/2/2008 